Federal Reserve Bank of Dallas

Globalization and Monetary Policy Institute

Working Paper No. 278

http://www.dallasfed.org/assets/documents/institute/wpapers/2016/0278.pdf

\title{
On What States Do Prices Depend? Answers From Ecuador ${ }^{*}$
}

\author{
Craig Benedict \\ SUNY Oswego \\ Mario J. Crucini \\ Vanderbilt University and NBER \\ Anthony Landry \\ Bank of Canada
}

August 2016

\begin{abstract}
In this paper, we argue that differences in the cost structure across sectors play an important role in the decision of firms to adjust their prices. We develop a menu cost model of pricing in which retail firms intermediate trade between producers and consumers. An important facet of our analysis is that the labor-cost share of retail production differs across goods and services in the consumption basket. For example, the price of gasoline at the retail pump is predicted to adjust more frequently and by more than the price of a haircut due to the high volatility in wholesale gasoline prices relative to the wages of unskilled labor, even when both retailers face a common menu cost. This modeling approach allows us to account for some of the cross-sectional differences observed in the frequency of price adjustments across goods. We apply this model to Ecuador to take advantage of inflation variations and the rich panel of monthly retail prices.
\end{abstract}

JEL codes: E3, E5, F3, F33

\footnotetext{
* Craig Benedict, State University of New York, OSWEGO, 450 Mahar, Oswego, NY 13126. 315-3123444. craig.benedict@oswego.edu. Mario J. Crucini, Department of Economics, Box 351819-B, Vanderbilt University, Nashville, TN 37235. 615-322-7357. mario.j.crucini@vanderbilt.edu. Anthony Landry, Bank of Canada, 34 Laurier Avenue West, Ottawa, ON K1A 0G9. 613-782-8785. anthonylandry@bankofcanada.ca. This paper was written while Mario Crucini was a visiting senior fellow at the Globalization and Monetary Policy Institute at the Federal Research Bank of Dallas. Mario Crucini gratefully acknowledges the financial support of the National Science Foundation. The views in this paper this paper are those of the authors and do not necessarily reflect the views of the Bank of Canada, the Federal Reserve Bank of Dallas or the Federal Reserve System.
} 


\section{Introduction}

A growing literature documents large cross-sectional variation in the frequency and size of price adjustment. To date, this literature has mostly focused on idiosyncratic shocks specific to individual firms to explain these patterns. For example, Dotsey et al. (1999) emphasize heterogeneous menu costs of price adjustment among firms, while Golosov and Lucas (2007) and Midrigan (2011) emphasize idiosyncratic productivity shocks. Both of these mechanisms generate cross-sectional variation in the frequency and size of price changes, but fail to address Boivin et al. (2009) finding that sector-specific shocks are important in explaining the frequencies and sizes of price changes. In particular, they find that disaggregated prices appear sticky in response to macroeconomic and monetary disturbances but flexible in response to sector-specific shocks.

In this paper, we present a simple theoretical model to explain these facts and provide microeconomic evidence to corroborate the underlying mechanism of our model. Specifically, we argue that differences in the cost structure across sectors play a central role in the price adjustment process. ${ }^{1}$ For instance, a local franchise selling haircuts will have a cost function that is relatively sensitive to local wage conditions whereas a local franchise that sells gasoline will have a cost structure that is relatively sensitive to the wholesale price of gasoline, which in turn is sensitive to the world price of oil (in domestic currency units). Local in the context of our application is a city within Ecuador.

To study how different sectors react to a given cost shock, we develop a two-factor menu cost model of a retail firm operating in a particular sector and selling goods or services in a particular city. Retail firms purchase intermediate inputs (potentially locally sourced or imported from elsewhere in their own country or abroad) and hire local labor to make goods and services available for sale in a local retail outlet. In most cities, some goods are locally sourced and others are imported. An example of the former is brewed coffee and of the latter, a Porsche. For services, an example of local sourcing is any service requiring the producer and consumer to be at arms-length (haircut, emergency room treatment, etc.); an example of a traded service is the broadcast of World Cup soccer.

To capture real frictions associated with intermediating trade between manufacturers

\footnotetext{
${ }^{1}$ Other papers have considered the effect of sector-specific shocks on aggregate and disaggregate prices, but none that we know of rely on the cost structure to explain the cross-sectional variations in the frequencies and sizes of price adjustments. Carvalho (2006) generalizes the Calvo model to allow for heterogeneity in price stickiness across sectors, while in the models of Gertler and Leahy (2008) and Mackowiak and Wiederholt (2009), firms pay more attention to firm-specific conditions.
} 
and final consumers, we incorporate heterogeneous distribution margins to create distinct pricing decision responses to an identical shock. As in most menu cost models of price adjustment, firms hold their prices constant until the difference between their optimal price and their current price is sufficient to justify paying the menu cost to adjust the price. However, in our model, the inducement to adjust prices depends both on the size of the shock to the manufacturing good price and its share in the total cost of making the good available to final consumers.

We use Ecuadorian data to test and calibrate the model because it has two attractive properties. First, Ecuador's macroeconomic history provides three regimes where the inflation rate, import price, and wages have distinct stochastic properties. Comparing across these three regimes allows us to relate changes in macroeconomic states to changes in the average frequency of price changes. Secondly, using a developing country allows larger shocks and movements in the input prices and inflation rate which can be exploited to more easily observe changes in the optimal pricing behavior of firms in the menu cost framework.

We first look at trends in the frequency of price adjustment to show that all firms reprice more frequently in a higher inflation environment. While this is common in the theoretical state-dependent pricing literature, a number of empirical studies, such as Klenow and Kryvtsov (2008), have shown that inflation and price adjustment frequencies are not highly correlated. Our empirical results are closer to those of Gagnon (2009), which used Mexican data to show that when annual inflation is greater than 10\%-15\% annually, the correlation between inflation and price adjustment frequency intensifies. Put differently, when inflation changes by a substantial amount, as is certainly true in Ecuador and Mexico, it is easier to detect the positive relationship between aggregate inflation and average price adjustment frequencies. In mild inflationary environments, idiosyncratic factors specific to particular goods or markets obscure the impact of aggregate inflation.

Our second finding relates to differences in the frequency of price adjustment across sectors within a given inflationary regime. In our data we find that traded goods always reprice more frequently than services. Our explanation is simple: the variance of real import prices is over three times larger than that of real wages. Therefore, firms that sell goods that utilize a larger share of traded goods in their production need to update prices more frequently due to the more volatile nature of their cost function.

This paper elucidates the states upon which a firm's price depends. Our results show that current state-dependent pricing models fail to account for key features present in the 
data. By incorporating firms cost structure into current state-dependent pricing models, policymakers can better predict price movements for individual firms and improve the effectiveness of monetary policy. While the relevance of our model is demonstrated in the case of Ecuador, our findings are likely to carry over to more stable, low inflation environments. For example, our model provides a natural explanation for the relatively frequent and volatile movements in food and energy, sectors which epitomize our definition of retail goods which are high in traded input content on a cost basis.

This paper is organized as follows. Section 2 provides the context for using Ecuador as a natural experiment and presents key stylized facts from the data. Section 3 lays out our theoretical framework which we use to generate a set of predictions for how prices should respond given the state of macroeconomic conditions in Ecuador. In Section 4, we calibrate and simulate the model to assess its ability to capture salient features of the observed frequencies of price changes across goods for three distinct inflationary environments experienced in Ecuador. Section 5 concludes.

\section{A Brief Monetary History of Ecuador}

In this section, we review Ecuadorian monetary history from 1995 to 2003 to give context to the model and present key stylized facts which help motivate our analysis. We show that the distribution of the frequency of price changes exhibits a stable crosssectional pattern across goods as Ecuador moves from one inflation regime to another. This pattern will serve as a key motivation for the model presented in Section 3.

\subsection{The Data}

Our primary source of data is a monthly database of retail prices from the National Institute of Statistics and Census (INEC), the official national statistical agency of Ecuador and a subdivision of its Central Bank. These data comprise monthly retail prices in 12 different Ecuadorian cities spanning both the Western Coastal region and the Central Sierra region, including both the country's capital, Quito, and largest city, Guayaquil. These prices cover a wide variety of goods and services of varying distribution shares, ranging from an automobile with a non-traded input share of 0.167 to postage for a letter, which has a non-traded input share of 1 . The data are described in detail in Peñaloza (2005). ${ }^{2}$

\footnotetext{
${ }^{2}$ The Ecuadorian micro-price panel was obtained from INEC (the national statistical agency of Ecuador) by Peñaloza (2005) who studied Ecuadorian real exchange rates with respect to the United
} 


\subsection{Three Inflation Regimes}

Prices were recorded monthly from January 1997 to April 2003. These years represent a tumultuous period in Ecuadorian history spanning three distinct inflation regimes. The first regime is referred to as the Moderate regime and represents a period of relative stability. At this time, Ecuador was on a crawling peg to the US dollar, and although Ecuador's monthly inflation rate of 2.8 percent seems high compared to a developed country like the US, it was typical for a Latin American country over this time period.

In mid-1998, Ecuador was hit with a series of exogenous, negative shocks. El Nino had negative effects on agriculture and the warming trend reduced the global price of oil, an important Ecuadorian export. Only a year prior, the Asian financial crisis appeared to leave developing and emerging markets susceptible to capital flight. Ecuadorian GDP per capita fell by more than 7 percent from 1998 to 1999. During our second regime, which we call the Crisis regime, Ecuador experienced a large bout of hyperinflation of approximately 5.1 percent per month which contributed to the paralysis of its economy.

Unable to reign in inflation using standard monetary policy actions, in January 2001, the Ecuadorian government announced that it would replace the Sucre by the US dollar for all retail transactions. The results of dollarization were impressive, with inflation falling from 5 percent to a mere 0.7 percent per month between 2001 and 2003, the end point of our sample.

Figure 1 plots our monthly inflation measure together with INEC's official Consumer Price Index. Our measure is an equally weighted average of inflation across all goods and cities. Comparing the two lines, it is obvious that our monthly database looks almost exactly like that of the official CPI. The inflation rate is shown in tri-color, displaying our three regimes: blue for the Moderate regime, red for the period of financial and exchange rate crisis known as the Crisis regime, and green for the Dollarization regime.

Table 1 presents our summary statistics across the three inflation regimes. The first row conveys the narrative history of inflation in Ecuador. In the first regime, inflation is very high compared to industrial countries, averaging 2.2 percent per month. In the second regime, during the financial and exchange rate crisis, inflation reaches hyperinflationary levels. The average is a bit deceptive in the sense that some inflationary spikes extended to more than 10 percent per month. The inflationary situation moderated in the third regime, with inflation stabilizing to 0.7 percent per month, presumably as a consequence of the dollarization together with a commitment to open trade and integration

States in his Ph.D. dissertation. 
with international capital markets.

\subsection{Price Changes in Ecuador}

We now turn to individual prices and present new stylized facts observed in our novel dataset. To help answer our question about the states upon which price adjustment depends, we begin with an analysis of the frequency of price change in Ecuador. Looking at Table 1, we see higher inflation periods are also periods with more frequent price changes consistent with a state-dependent or menu-cost theory of price adjustment. We see this pattern consistently across the three regimes of our sample with the frequency of price changes increasing from $50 \%$ (Regime 3) to $54.1 \%$ (Regime 1) and then to $67.8 \%$ (Regime 2) as we move from the lowest to highest inflation regime. These frequencies are about twice as high as those reported in Nakamura and Steinsson (2008) for the United States. In addition, this strong correlation between frequency of price change and inflation runs counter to much of the empirical literature (e.g. Klenow and Kryvtsov (2008)). Both of these differences are accounted for by the fact that inflation is much higher in Ecuador than in the US, even during the most stable period of dollarization. A more appropriate comparison of inflation rates is Gagnon (2009), who studies the frequency of price changes in Mexico from 1994 to 2002 and shows inflation is strongly correlated with price change frequency when inflation is over 10\%. Even during the stable Dollarization regime, Ecuadorian annual inflation is about $9 \%$ annually.

As other authors have pointed out, the frequency of price adjustment differs substantially across items in the consumption basket. This heterogeneity of frequencies across goods is a universal feature of micro-price data. An important question to ask is whether the cross-sectional variance in frequencies reflects economic structure that macroeconomists should be building into their models or uninteresting noise. We suspect that structure underlies these patterns.

As an intuitive metric to elucidate such structure we ask if the frequency of price adjustments maintains its cross-sectional pattern as we move from one regime to another. Figure 2 accomplishes this by plotting the frequency of price adjustment by good in our micro-sample as individual data points. The x-coordinates of this figure are the frequencies of price adjustment in Regime 1, the sample with the inflation rate closer to the historical mean. The $\mathrm{y}$-coordinates for the red and green dots are frequencies in the Crisis regime (Regime 2) and the Dollarization regime (Regime 3), respectively. The higher (lower) average adjustment frequencies in Regime 2 (Regime 3) are evident with the red (green) 
scatter lying above (below) the 45- degree line. Here we see an underlying pattern to the data across goods: The cross-sectional distribution of price-adjustment frequencies is preserved across eras with a slightly elevated (reduced) mean price-adjustment frequency in high (low) inflation regime compared to normal times. This pattern is inconsistent with menu-cost models in which the heterogeneity in price adjustments comes from firms drawing randomly from a common distribution of menu costs (e.g., Dotsey et al. (1999) and the open-economy versions of Landry $(2009,2010)$ ) or from a common distribution or productivity shocks (e.g., Golosov and Lucas (2007)). In these cases, we would expect a cloud of points tightly clustered around the mean frequency in each regime with little or no pattern in relation to the 45 degree line.

Evidence of a structural relationship comes from the fact that the cross-sectional distribution of price-adjustment frequencies is preserved across regimes. That is, the frequencies of price changes across goods is strongly positively correlated across regimes (i.e., the green and red scatter diagrams show strong positive correlation with each other). What this suggests is that there is some factor specific to an individual good that induces more or less frequent price adjustments and this has little to do with the inflation regime. Next, we turn to our explanation for this stable cross-sectional distribution of priceadjustment frequencies.

\section{The Model}

Like traditional menu-cost models, firms must pay a fixed menu cost in order to adjust their price. However, unlike these models, each firm's cost function may have a different weight on its factors of production and therefore, different exposure to different cost components. Naturally, then, firms with a higher cost share of the more volatile input price will adjust their prices more frequently. In most macroeconomic settings, the more volatile input price in retail goods is the traded input component. Food and energy provide good examples relative to labor-intensive items such as services. We turn, now, to the structural details of the model.

\subsection{Menu Cost Model of Price Adjustment}

We develop a partial equilibrium model in which a continuum of firms belongs to a sector that combines labor (i.e., retail services) and a wholesale good purchased in global markets to produce a differentiated final good. The production function for firm $i$ is 


$$
y_{i t}=l_{i t}^{\alpha_{i}} m_{i t}^{1-\alpha_{i}}
$$

where $y_{i t}$ is the final good the consumer purchases, $l_{i t}$ denotes retail services involved in making the good available to the final consumer and $m_{i t}$ is the intermediate imported good.

Consumers have CES preferences over goods and thus the demand for the good $i$ is:

$$
y_{i t}=y\left(\frac{p_{i t}}{P_{t}}\right)^{-\theta}
$$

where $p_{i t}$ is the nominal price of good $i$ relative to the CPI price index. Real aggregate demand (and income) is $y$, and $\theta$ is the elasticity of demand. We normalize output to unity in what follows.

Firm $i$ maximizes the expected discounted value of its profits:

$$
E_{t} \sum_{s=t}^{\infty} d_{t, s} \pi_{i s}
$$

where $d_{t, s}$ is the discount factor between period $t$ and future period $s$ and $\pi_{i s}$ is the flow level of real profits (nominal profits divided by the CPI price level) for the firm in period $s$. Flow profits in real terms equal,

$$
\pi_{i t}=p_{i t} y_{i t}-w_{t} l_{i t}-p_{i t}^{m} m_{i t}-\chi w_{t} I_{i t}
$$

where $I_{i t}=1$ if the firm adjusts its price $p_{i t}$ and 0 otherwise.

We normalize the real wage and the import price such that optimal real price equals unity on average in the steady-state. The indexation of the nominal wage means that as a firm leaves its nominal price constant, demand for its product increases and real profits also rise provided $\theta>1$ (when the demand elasticity is unitary, the increase in demand generated by the falling price of the good exactly offsets the effect of the price decline on real revenue, so real revenues remain unchanged. The firm then decides on the extensive (timing) and the intensive (size) margins of price adjustment to maximize the expected discounted value of profits.

The pricing decision rule of a firm in our model has two dimensions: First, the price adjustment decision is a function of the import price and the aggregate price level. Second, the size of the inaction region and the magnitude of the price jumps are different for each 
component of marginal cost and depend on the cost share of labor and traded inputs into production.

To see this more clearly, consider a log-linearized version of the nominal cost function implied by the model:

$$
c_{i t}=\alpha_{i} w_{t}+\left(1-\alpha_{i}\right) p_{i t}^{m}
$$

The two state variables are the wage rate in Ecuador, $w_{t}$, and the import price index, $p_{i t}^{m}$.

In our setting, the variance of the marginal cost function depends on the variance of wages, the variance of import prices, and their covariance. It also depends on the cost share of the two inputs, $\alpha_{i}$. In Golosov and Lucas (2007), the frequency of price changes is increasing in the variance of the microeconomic productivity shocks experienced by firms because this translates into higher variance in marginal cost. In our setting, the frequency of price adjustments is rising in the cost share of the imported input because these microeconomic prices tend to be more volatile than the nominal wage. Moreover, import prices tend to be more volatile than domestic prices, on average, and more so the more complete is exchange rate pass-through. A similar point was made in Crucini, Shintani and Tsuruga (2013). Namely, flexible prices amplify the transmission of real shocks across locations while sticky prices amplify the transmission of nominal shocks.

Figure 3 shows this connection in the Ecuadorian data. In the figure, each dot represents a different good in the dataset. The x-coordinate is the distribution share of the good and the y-coordinate is the frequency of price adjustment. In all three regimes and in the full sample we see an inverse relationship between the two variables. As the distribution share increases, firms are less likely to adjust their prices, presumably because movement in the import price outweighs movement in wages. The slope becomes steeper in both the crisis regime and the full sample. With this theoretical discussion as background we turn to the calibration of our benchmark parameterization.

\subsection{Calibration of Shock Parameters}

Due to the lack of monthly wage and import price data available for Ecuador, we make two simplifying assumptions. The first is that the price of haircuts can be used as a proxy for the wage. After setting the nominal wage, $W_{t}$, equal to the price of haircuts, we rely on the model, our observed retail price, $P_{i t}$, and estimates of the distribution cost share to back out the import price, $P_{i t}^{m}$. That is, the empirical counterpart to the cost function is: 


$$
p_{i t}=\alpha_{i} w_{t}+\left(1-\alpha_{i}\right) p_{i t}^{m}
$$

where lowercase denotes the log of the variable. Using simple alegbra will give us the import price:

$$
p_{i t}^{m}=\frac{p_{i t}-\alpha_{i} w_{t}}{\left(1-\alpha_{i}\right)}
$$

Using $p_{i t}^{m}$, we then estimate the parameters in our model from the following system of equations.

$$
\begin{gathered}
p_{t}=\mu_{r}+p_{t-1}+\epsilon_{t} \\
p_{i t}^{m}-p_{t}=\mu_{i m}+p_{i t-1}^{m}-p_{t-1}+\nu_{i t}
\end{gathered}
$$

where $p_{i t}^{m}$ represents the nominal import price. The error terms are assumed to be normally distributed with mean 0 and variances of $\sigma_{\epsilon}^{2}$ and $\sigma_{i \nu}^{2}$. Table 2 gives the results of this estimation excercise. Figure 4 is a histogram showing the estimated variances of the import price shocks, $\sigma_{i \nu}^{2}$ for each of the regimes and the full sample. The y-axis shows the number of goods in each bucket corresponding to the values along the $\mathrm{x}$-axis. As expected, the import price shocks are much more widely distributed in regime 2 and the full sample. This dispersion of the import price shocks is what drives our results and leads firms with a greater reliance on traded goods to adjust their price more frequently.

Based on our estimation exercise, a number of facts are readily apparent. The most significant is that the median import price shock of 0.005 is over four times larger than the inflation rate shocks of 0.0013 in the full sample. The dominance of import price shocks relative to inflation shocks generates a prediction that goods with larger distribution shares (i.e., retail labor) will exhibit less frequent price changes due to a lower overall variability in the firm's cost function.

Our calibration parameters are displayed in Table 2. We allow the mean inflation rate, the variance of inflation and the variance of the relative price of imports to vary across regimes to match the historical data of Ecuador. The distribution cost shares and the menu cost do not change over time. The distribution cost shares are taken from US NIPA estimates by sector and matched to the Ecuadorian retail price data by assigning each good or service to a US NIPA sector. The distribution shares range from 0.19 for gasoline to 0.85 for haircuts. The median across the 223 goods and services in the Ecuadorian micro-panel is 0.52. Following the literature, menu costs are calibrated to 
$1.5 \%$ of labor income to match the frequency of price adjustment for the median good in the full sample. Given the median frequency of price changes is 0.6 , roughly $0.9 \%$ of aggregate labor income is spent on price adjustment by retail firms.

\section{Results}

Having estimated the stochastic processes for the two components of the firm's cost function, we are in a position to compare our model's predictions for the frequencies of price change across sectors and regimes to the micro-data.

To gain some intuition for the relationship between menu costs and price adjustment, Figure 5 plots the policy function for a representative firm facing a constant import price. This is a common figure within the menu-cost literature, which shows the price-adjustment cutoffs as the firm's real price fluctuates around the optimal price, given by $\frac{p_{t-1}}{P_{t}}$.

Our model, however, differs from conventional menu cost models because firms have different price-adjustment cutoffs based on their distribution cost share. To show this, Figure 6 plots the policy functions of three firms, each with a different distribution cost share. In this graph the aggregate price level $P_{t}$ is held constant. We see that when firms choose to reset to the optimal price, they choose $p_{t}$ such that it is equal to $\left(p_{i t}^{m}\right)^{1-\alpha}$. Furthermore, we observe that as the distribution share $\alpha_{i}$ increases, firms have a wider band of inaction and therefore become less sensitive to a traded input shock. Therefore, a firm with a higher distribution cost share will experience a smaller marginal revenue deviation, thus reducing the likelihood that the firm reprices.

In our first exercise, we test the ability of our model to match the median frequency of prices changes across all three regimes. Here we restrict the model to have only aggregate price level shocks and abstract from heterogeneity in the distribution share across goods. That is, the distribution share of retail production is set at 0.52 , the median across goods. Figure 7 presents the median frequencies of price adjustments by regime for each city in the Ecuadorian micro-panel as well as the predictions of the baseline calibration of the model. The black stars are the predictions from the model while the red, blue and green dots are measured using the micro-data. For example, the cluster of green dots represents the median frequencies of price adjustments across goods, city-by-city for the dollarization regime (Regime 3). With inflation of about 3 percent per quarter, the frequency of price adjustments is about 50 percent per month. Inflation during the financial crisis is above 14 percent per quarter and the median frequencies are between 60 to 70 percent. The 
menu cost is parameterized to match the overall average frequency, which is the third black star from the bottom left. We see that the model also fits the Crisis regime, but underestimates the frequency of price adjustments in Regime 3, the Dollarization regime.

Our next exercise is to see how the model fares in accounting for the heterogeneity of price-adjustment frequencies. Figure 8 displays the simulated frequency of price adjustments averaged over each distribution share. Each dot represents a distribution share across the regimes-in the same fashion as the data were presented in Figure 2. Regime 1's simulations are on the x-axis and Regime 2's and 3's are the y-coordinates. It should be kept in mind that we have fewer distribution shares than goods, which limits to some extent the cross-sectional variance that results. That being said, the variation is much less than we saw in Figure 3 earlier. We suspect that this is partly due to our adherence to a common variance of import price shocks across goods. While a full model could potentially include heterogeneity in productivity shocks and possibly wages as well, we abstract from these issues and our results therefore are likely to have less variability as a result.

Figure 9 displays the frequency of price adjustment for each good in the model compared to its distribution share on the x-axis. All regimes show a negative correlation between a good's distribution share and its frequency of price adjustment. Our model not only accounts for the fact that goods maintain a certain frequency of price adjustment pattern across regimes, but also it distinguishes which goods are more likely to reprice based on their cost structure. Besides the general downward trend of the slope, we can again observe the under-prediction of frequency in the Dollarization regime and the overprediction in the Crisis regime. The lines in the figure are fitted values from a linear regression of the frequencies of the price changes in the Ecuadorian data on sector-level distribution shares from the US NIPA. The appendix provides more details about these constructs.

Together these results indicate that our menu cost model can account for many of the stylized facts we found in Section 2 regarding the price adjustment process. In addition to matching the positive correlation between frequencies of price changes and aggregate inflation, our structural model provides a novel explanation for the different frequencies of price changes observed across the distribution of goods in the CPI. 


\section{Conclusion}

In making decisions about changes in the Federal Funds rate, it is essential that monetary policymakers distinguish generalized inflationary impulses from changes in relative prices that may affect some, but not all market prices. The structure of our model helps to elucidate these differences. Changes in the prices of imported goods are often large and induce frequent changes in the retail prices of these goods. Essentially, this is why food and energy are typically excluded in measures of core inflation. The typical explanation for the volatility of these prices is that the markets for them are subject to particularly large shocks. Our approach generalizes this conventional wisdom by recognizing that final goods have distinct production functions in the sense of requiring different intensities of retail labor in making them available to final consumers. This allows us to parse the inflationary impulse of, say, an indexed wage (typically the cost-push dimension of monetary policy) from shocks that are idiosyncratic to the good or sector (such as imported goods). Ecuador provides an ideal setting to explore this mechanism by virtue of highfrequency micro-price data by good and city spanning a varied inflationary experience. Our hope is that our work will motivate similar studies in other countries to validate the menu cost model developed here in a broader cross-section of nations and in inflationary environments closer to that of the United States. 


\section{References}

[1] Ahlin, Chris and Mototsugu Shintani. 2007. "Menu Costs and Markov Inflation: A Theoretical Revision with New Evidence "Journal of Monetary Economics, 54 (2007), 753-784.

[2] Beckerman, Paul. 2001. "Dollarization and Semi-dollarization in Ecuador." World Bank Working Paper No. 2643.

[3] Bils, Mark and Peter J. Klenow. 2004. "Some Evidence on the Importance of Sticky Prices "The Quarterly Journal of Economics, 112(5), 947-985.

[4] Boivin, Jean, Marc P. Giannoni, and Ilian Mihov. 2009. "Sticky Prices and Monetary Policy: Evidence from Disaggregated US Data "The American Economic Review, $99(1), 350-384$.

[5] Burstein, Ariel, Martin Eichenbaum and Sergio Rebelo. 2005. "Large Devaluations and the Real Exchange Rate." Journal of Political Economy, 113, 742-784.

[6] Carvalho, Carlos. 2006. "Heterogeneity in Price Stickiness and the Real Effects of Monetary Shocks" The B.E. Journal of Macoeconomics, 6(3).

[7] Crucini, Mario J., and Anthony Landry, 2012. "Accounting for Real Exchange Rates Using Micro-data." NBER Working Paper No.17812.

[8] Crucini, Mario J., Mototsugu Shintani, and Takayuki Tsuruga. 2013. "Noisy Information, Distance and Law of One Price Dynamics Across US Cities." NBER Working Papers No.17815.

[9] Crucini, Mario J. and Hakan Yilmazkuday. 2013. "Understanding Long-run Price Dispersion." NBER Working Paper No.18811.

[10] Dotsey, Michael, Robert G. King, and Alexander L. Wolman 1999. "State-Dependent Pricing and the General Equilibrium Dynamics of Money and Output " The Quarterly Journal of Economics, 114(2), 655-690.

[11] Eden, Benjamin 2001. "Inflation and Price Adjustment: An Analysis of Microdata." Review of Economic Dynamics, 4 (2001), 607-635.

[12] Gagnon, Etienne. 2009. "Price Setting During Low and High Inflation: Evidence from Mexico."The Quarterly Journal of Economics, 124(3), 1221-1263. 
[13] Gertler, Mark and John Leahy. 2008. "A Phillips Curve with an Ss Foundation " Journal of Political Economy, 116(3), 533-572.

[14] Golosov, Mikhail and Robert E. Lucas. 2007. "Menu Costs and Phillips Curves." Journal of Political Economy, 115 (2007), 171-199.

[15] Gopinath, Gita and Oleg Itskhoki. 2010. "Frequency of Price Adjustment and Passthrough." The Quarterly Journal of Economics, 125 (2010), 675-727.

[16] Klenow, Peter J. and Oleksiy Kryvtsov. 2008. "State-dependent or Time-dependent Pricing: Does It Matter for Recent U.S. Inflation?"The Quarterly Journal of Economics, 123(3), 863-904.

[17] Landry, Anthony. 2009. "Expectations and Exchange Rate Dynamics: A Statedependent Pricing Approach "Journal of International Economics, 78(1), 60-71.

[18] Landry, Anthony. 2010. "State-dependent Pricing, Local-currency Pricing, and Exchange Rate Pass-through "Journal of Economic Dynamics and Control, 34(10), 18591871.

[19] Mackowiak, Bartosz and Miko Wiederholt. 2009. "Optimal Sticky Prices under Rational Inattention " American Economic Review, 99(3), 769-803.

[20] Midrigan, Virgiliu. 2011. "Menu Costs, Multiproduct Firms, and Aggregate Fluctuations "Econometrica, 79(4), 1139-1180.

[21] Nakamura, Emi and Jon Steinsson. 2008. "Five Facts About Prices: A Reevaluation of Menu Cost Models." Quarterly Journal of Economics, 123(4), 1415-1464.

[22] Nakamura, Emi and Jon Steinsson. 2010. "Monetary Non-neutrality in a Multisector Menu Cost Model." Quarterly Journal of Economics, 125(3), 961-1013.

[23] Peñaloza-Pesantes, Roberto. 2005. "Dollarization and Price Dynamics." Ph.D. Dissertation, Vanderbilt University. 
Table 1. Summary of Monthly Price Facts

\begin{tabular}{lcccc}
\hline & $\begin{array}{c}\text { Full sample } \\
1997: 01-2003: 04\end{array}$ & $\begin{array}{c}\text { Regime 1 } \\
1997: 01-1998: 07\end{array}$ & $\begin{array}{c}\text { Regime 2 } \\
1998: 08-2000: 12\end{array}$ & $\begin{array}{c}\text { Regime3 } \\
\text { 2001:01-2003:04 }\end{array}$ \\
\cline { 2 - 5 } Inflation & $2.8 \%$ & $2.2 \%$ & $5.1 \%$ & $0.7 \%$ \\
Price adjustment frequency & $57.7 \%$ & $54.1 \%$ & $67.8 \%$ & $50.0 \%$ \\
Price increases & $43.2 \%$ & $42.8 \%$ & $54.7 \%$ & $31.8 \%$ \\
Price declines & $14.4 \%$ & $11.3 \%$ & $13.1 \%$ & $18.2 \%$ \\
Size of price changes & $7.1 \%$ & $5.9 \%$ & $9.8 \%$ & $3.9 \%$ \\
\hline
\end{tabular}

Size of price adjustments are average absolute values across goods and time periods.

Table 2: Stochastic Properties of Shocks

\begin{tabular}{lcccc}
\hline & $\begin{array}{c}\text { Full sample } \\
\text { Inflation, } \mu\end{array}$ & Regime 1 & Regime 2 & Regime 3 \\
\cline { 2 - 5 }$\sigma_{\eta}$ & $2.8 \%$ & $2.2 \%$ & $5.1 \%$ & $0.7 \%$ \\
$\sigma_{\nu}$ & 0.0013 & 0.0002 & 0.0021 & 0.0002 \\
& 0.0050 & 0.0019 & 0.0089 & 0.020 \\
$\alpha_{i}$ & & & & \\
& Haircut & 0.85 & Menu cost & $1.5 \%$ \\
& Gasoline & 0.19 & $\lambda$ & 0.60 \\
& Median & 0.52 & $\mathrm{E}(\mathrm{Menu})$ & $0.9 \%$ \\
\hline
\end{tabular}


Figure 1: Monthly CPI inflation in Ecuador by Regime

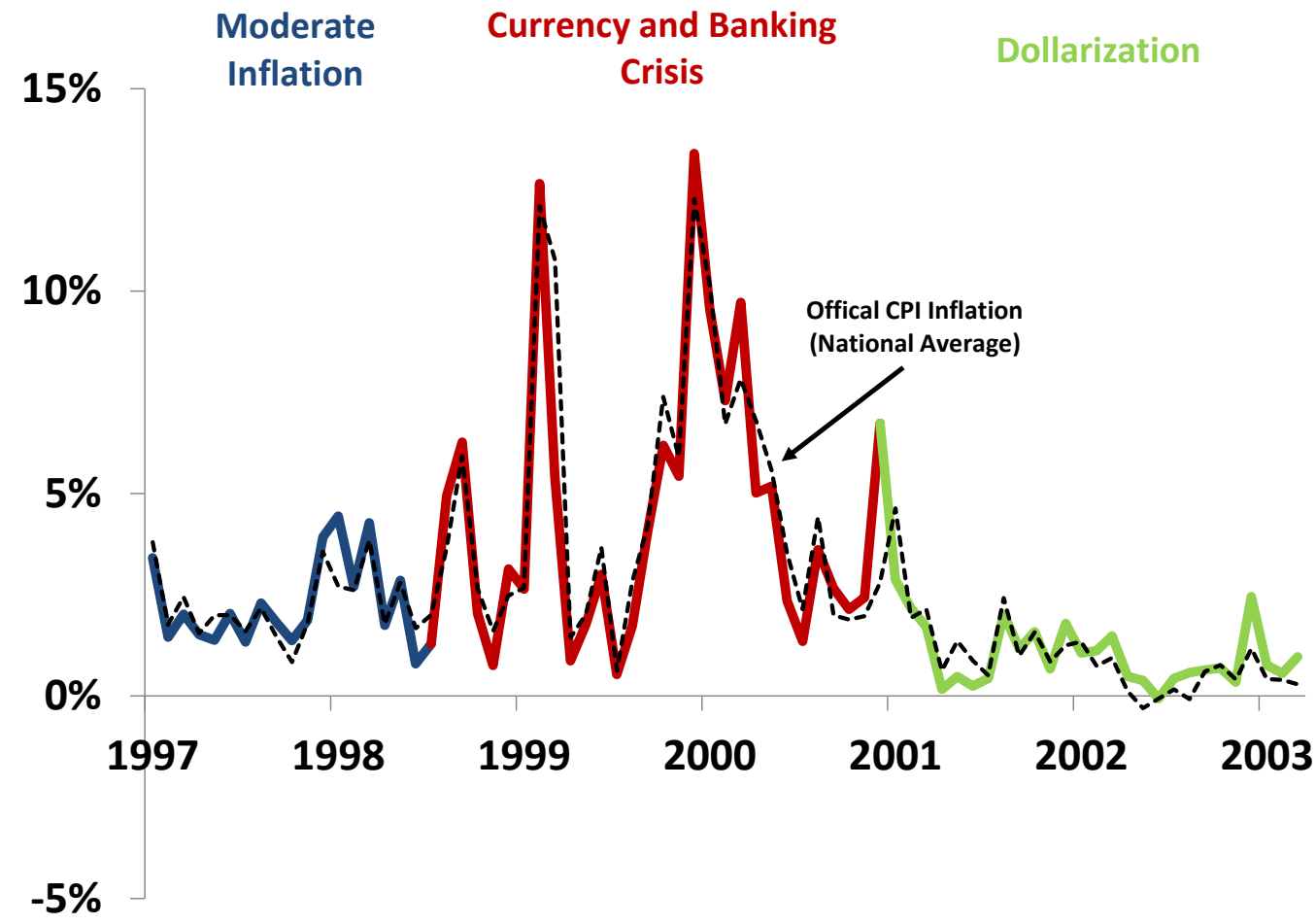

Monthly inflation rate over the sample period of January 1998 to April 2003, calculated as an equally weighted average of inflation across all goods and cities from our dataset. The black line represents the official CPI from INEC, Ecuador's national statistical agency. 
Figure 2: Goods-by-goods frequencies of price changes in the data

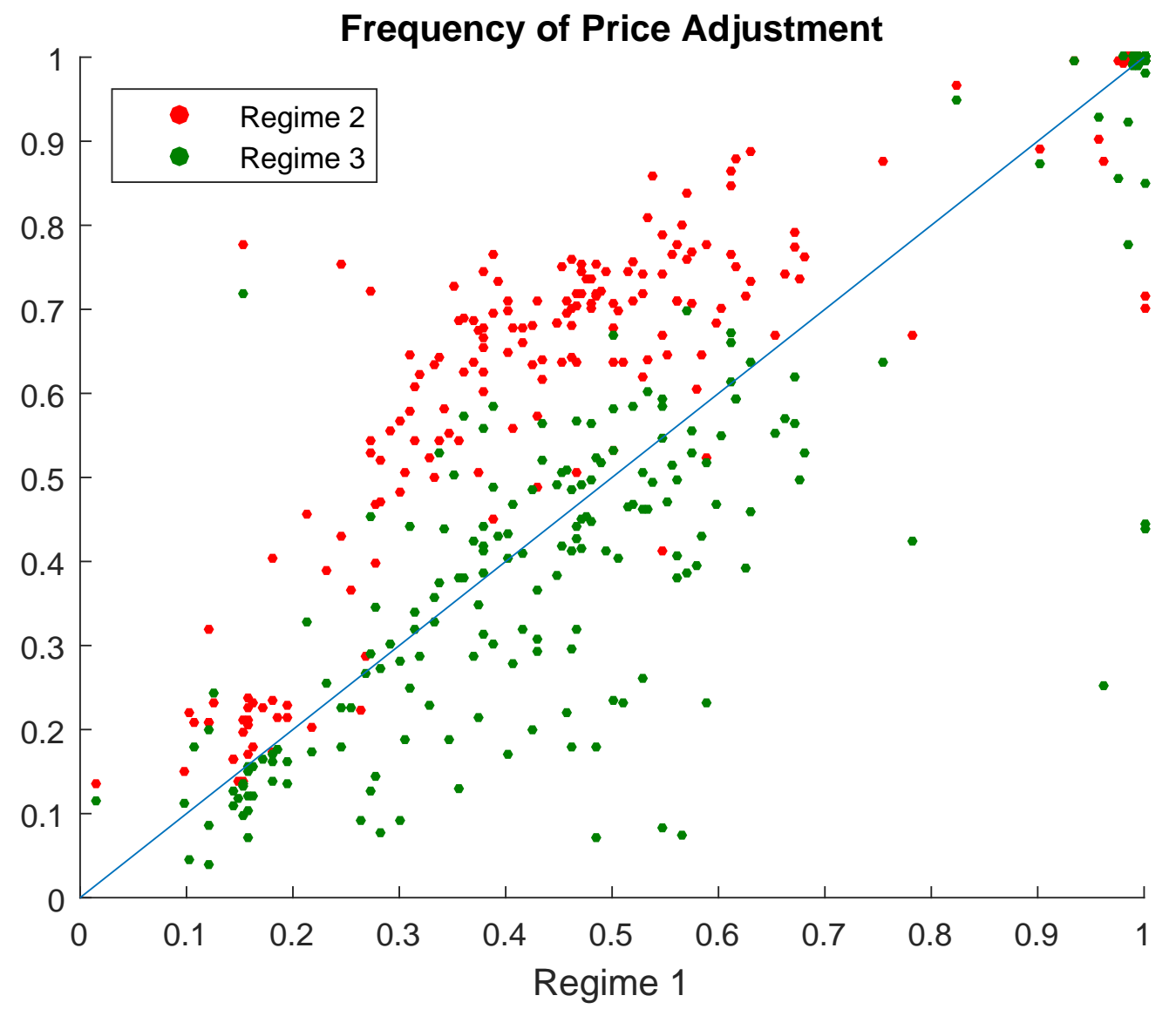

Comparison of price adjustment frequencies across regimes. Each dot represents a specific good. The x-coordinates represent the price-adjustment frequencies in Regime 1, while the y-coordinates represent the price adjustment frequencies in the Crisis regime (Regime 2) and the Dollarization regime (Regime 3). 
Figure 3: Frequencies of price changes by non-traded input share
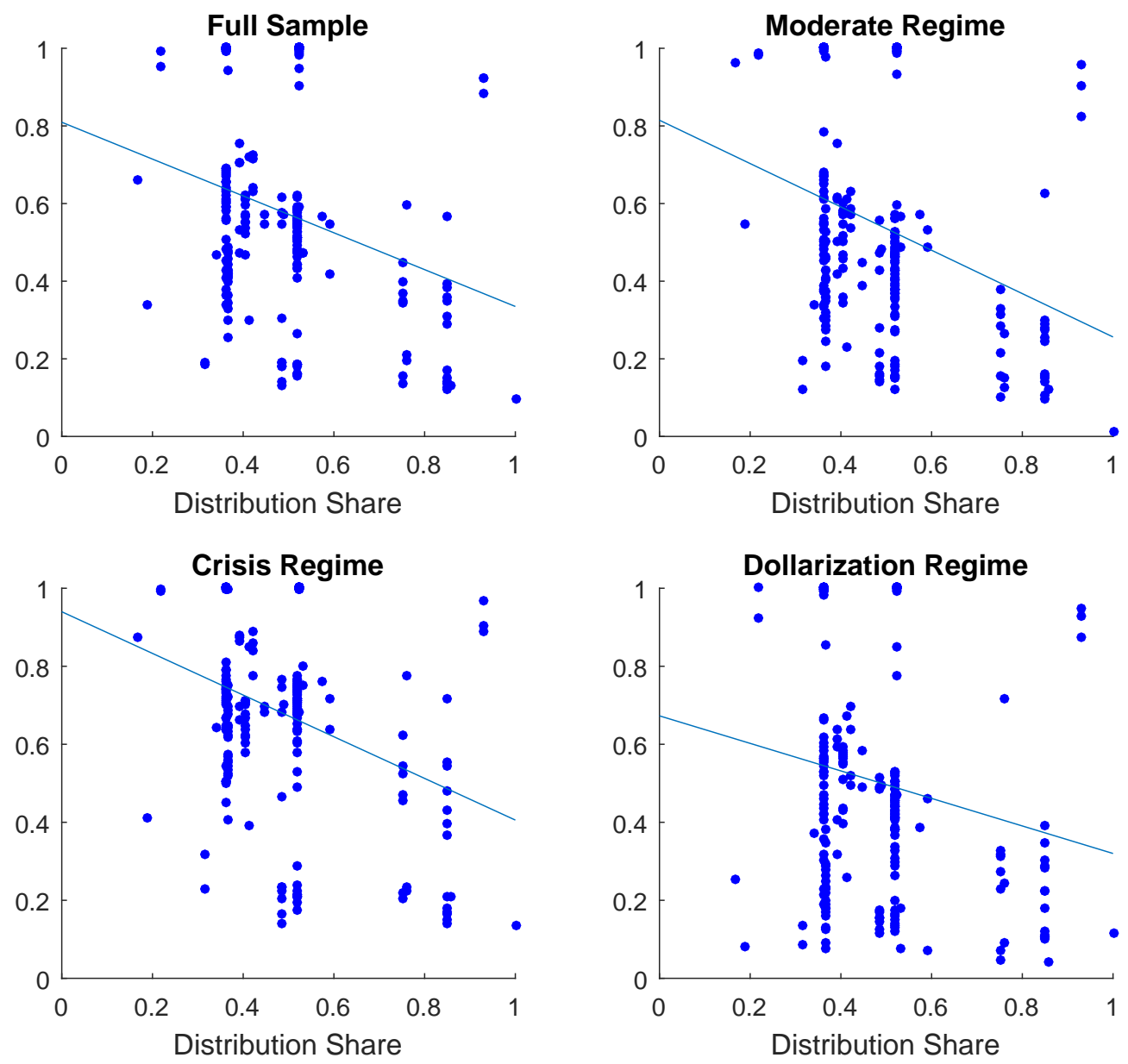

The frequency of price adjustment in each regime by distribution margin. Goods with a larger non-traded input share are less likely to reprice in each of the three regimes and the full sample. 
Figure 4: Estimated distribution of import price shocks
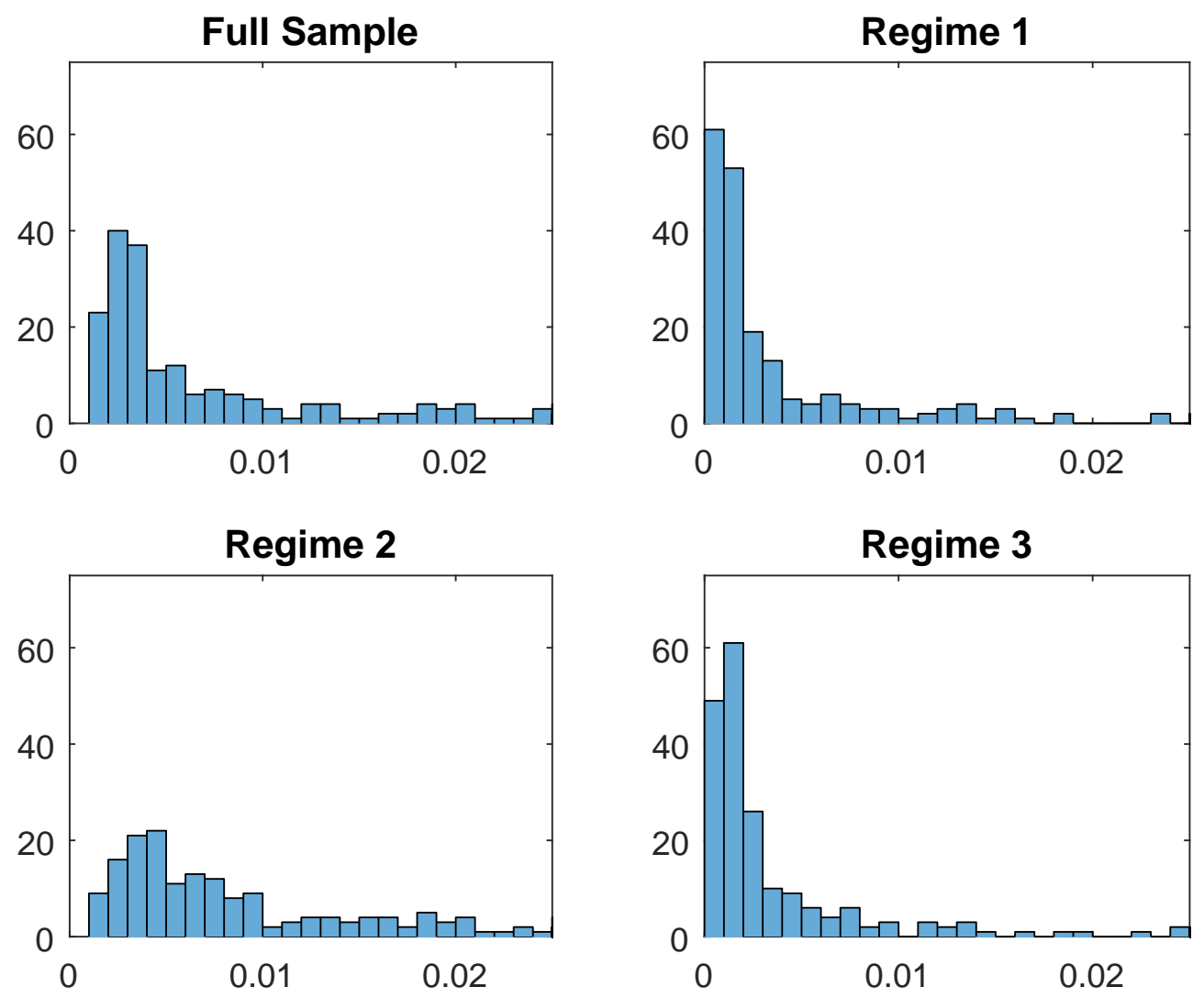

The distribution of import price shocks. Eras 1 and 3 have a larger number of goods with import price shocks close to 0. 
Figure 5: Policy function for a representative firm

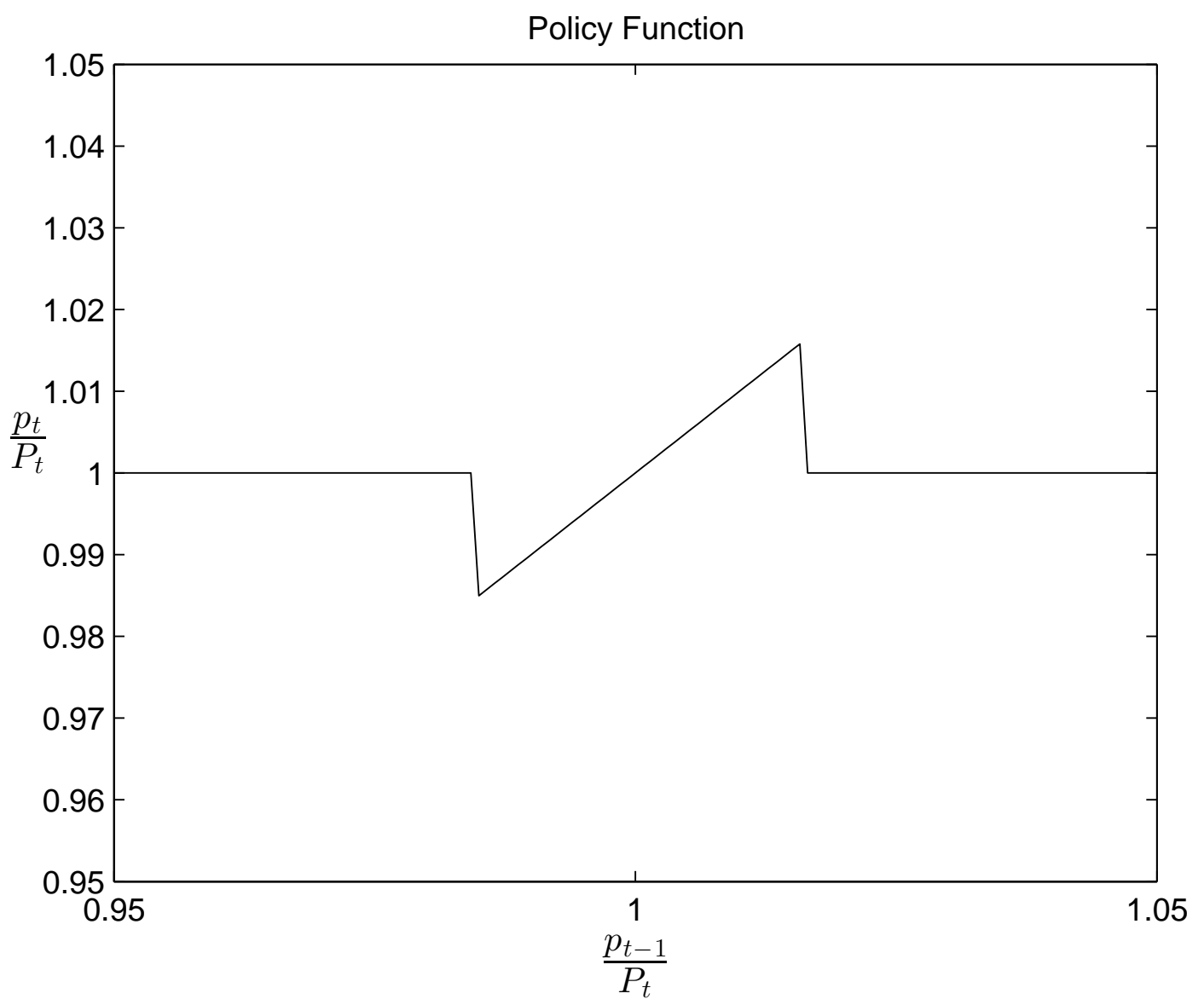

Representative policy function for a firm with $\alpha=0.167$ holding the import price at unity. 
Figure 6: Policy function for three representative firms

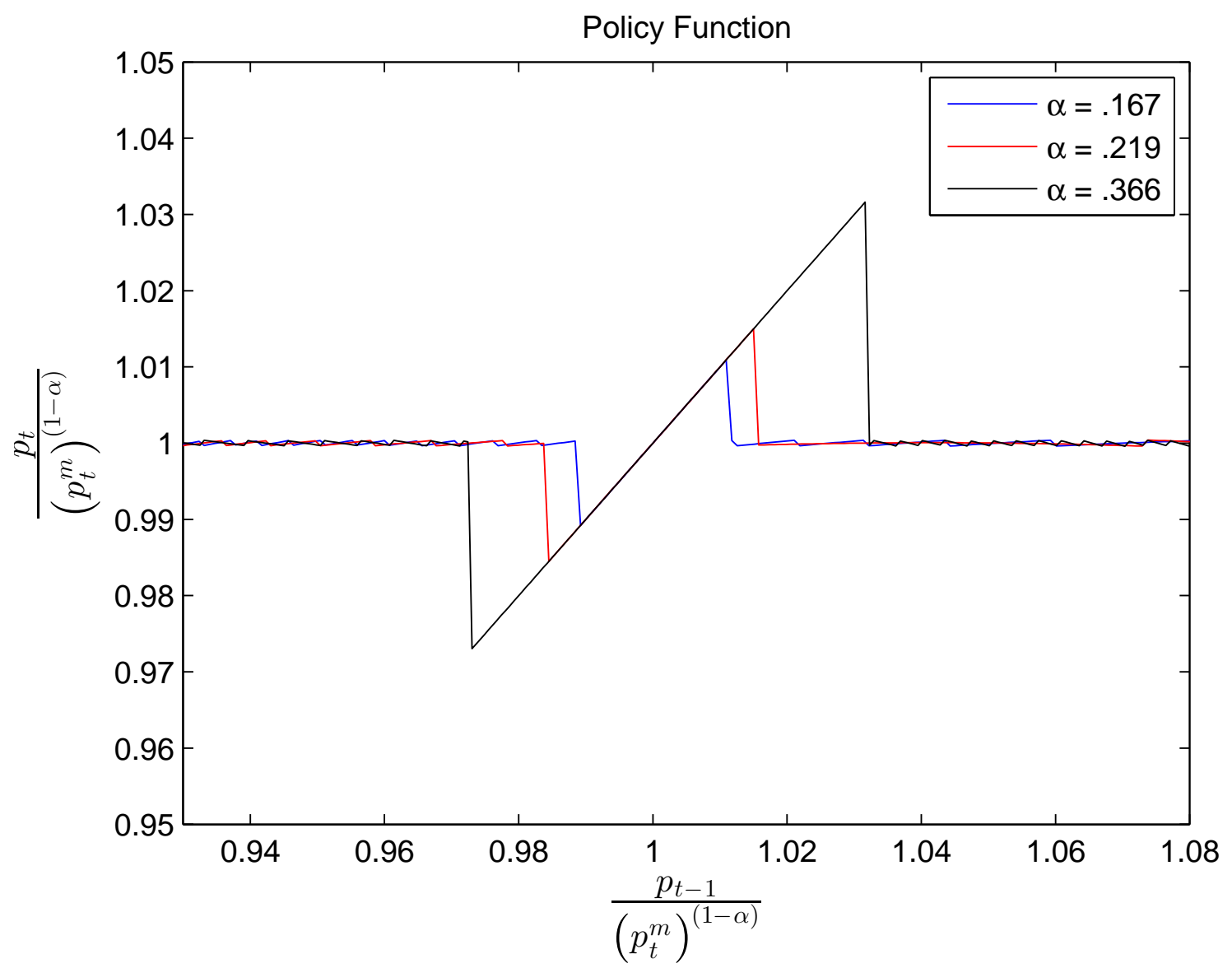

Representative policy function for 3 firms holding the aggregate price level constant, each with a different non-traded input share assuming $P_{t}=1$. Figure 6 shows that firms' price adjustment cutoffs is based on a firms' non-traded input share The figure shows that firms with lower distribution shares are less sensitive to a change in an import price shock. 
Figure 7: Median price change adjustment by regime, data, and model

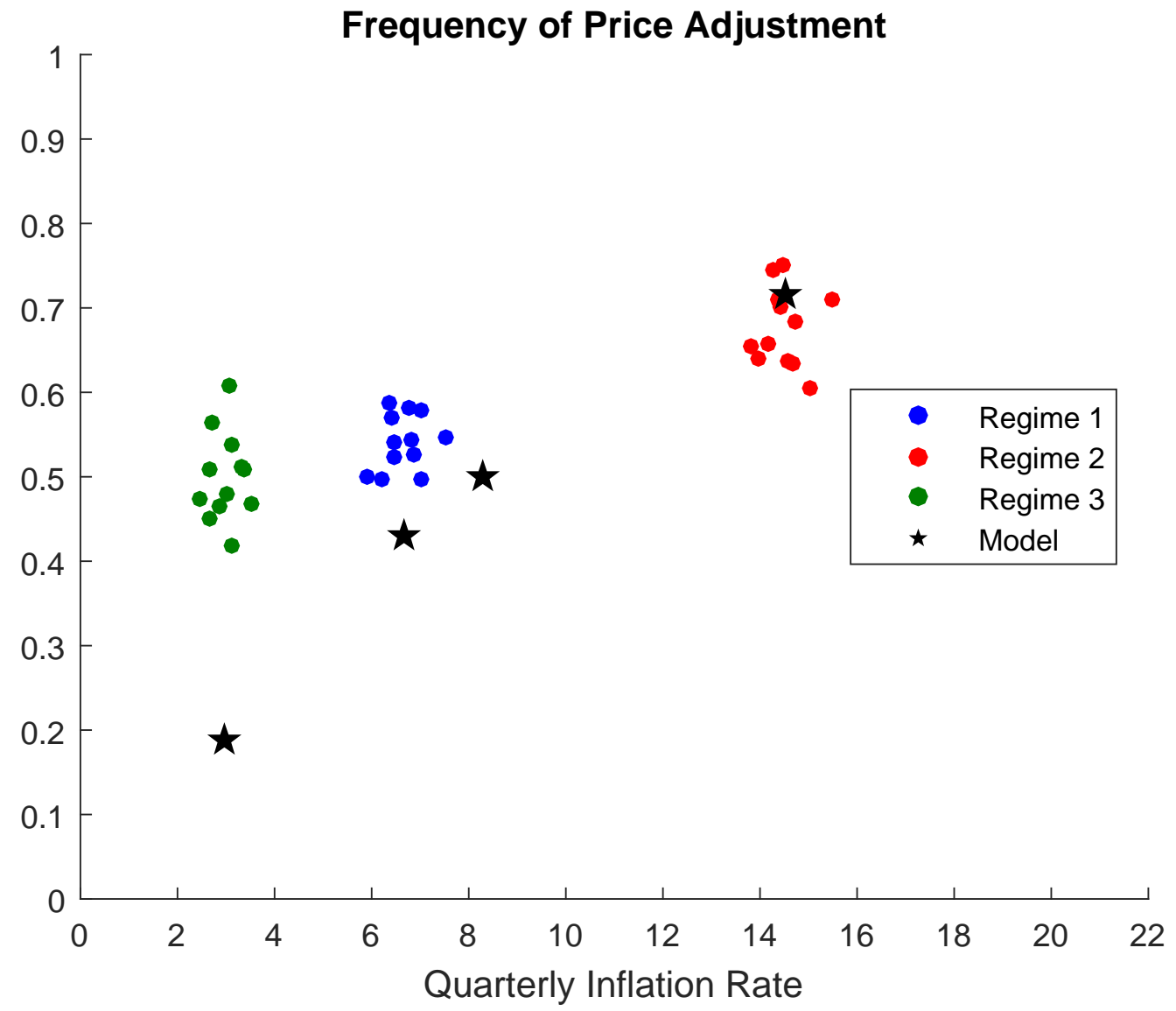

Comparison of the frequency of price adjustment in both the data and the model. The black stars represent the model's predicted frequency for the median good in each regime. The colored dots represents the median frequency of price adjustment in each of the 12 cities in Ecuador. 
Figure 8: Monthly CPI inflation in Ecuador by Regime

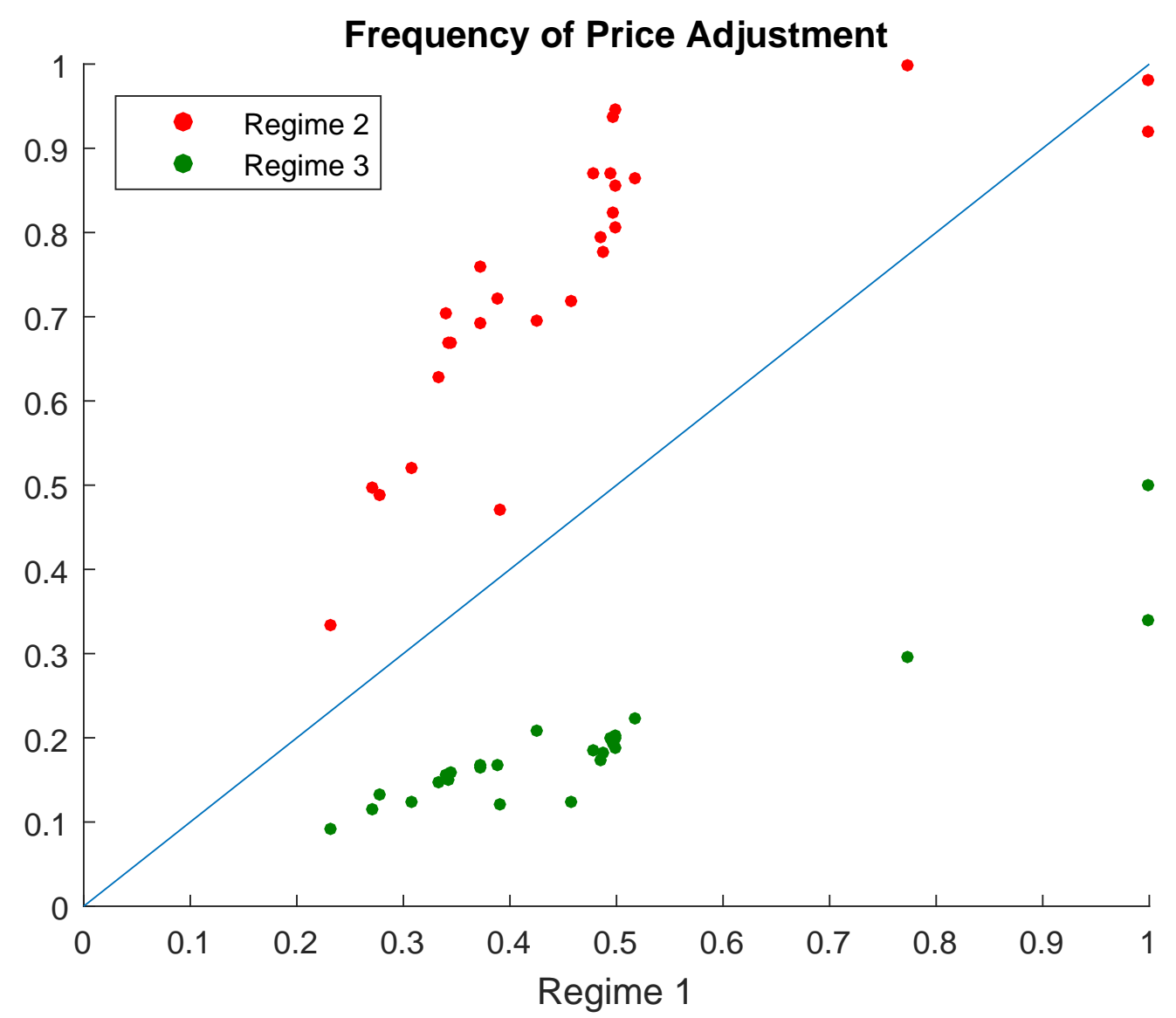

Comparison of the frequency of price adjustment across regimes in the model. Each dot represents a specific good. The $\mathrm{x}$-coordinate reflects the good's frequency of price adjustment in Regime 1 while its y-coordinate represents the same good's frequency of price adjustment in Regime 2 or Regime 3. 
Figure 9: Frequencies of price changes by non-traded input share
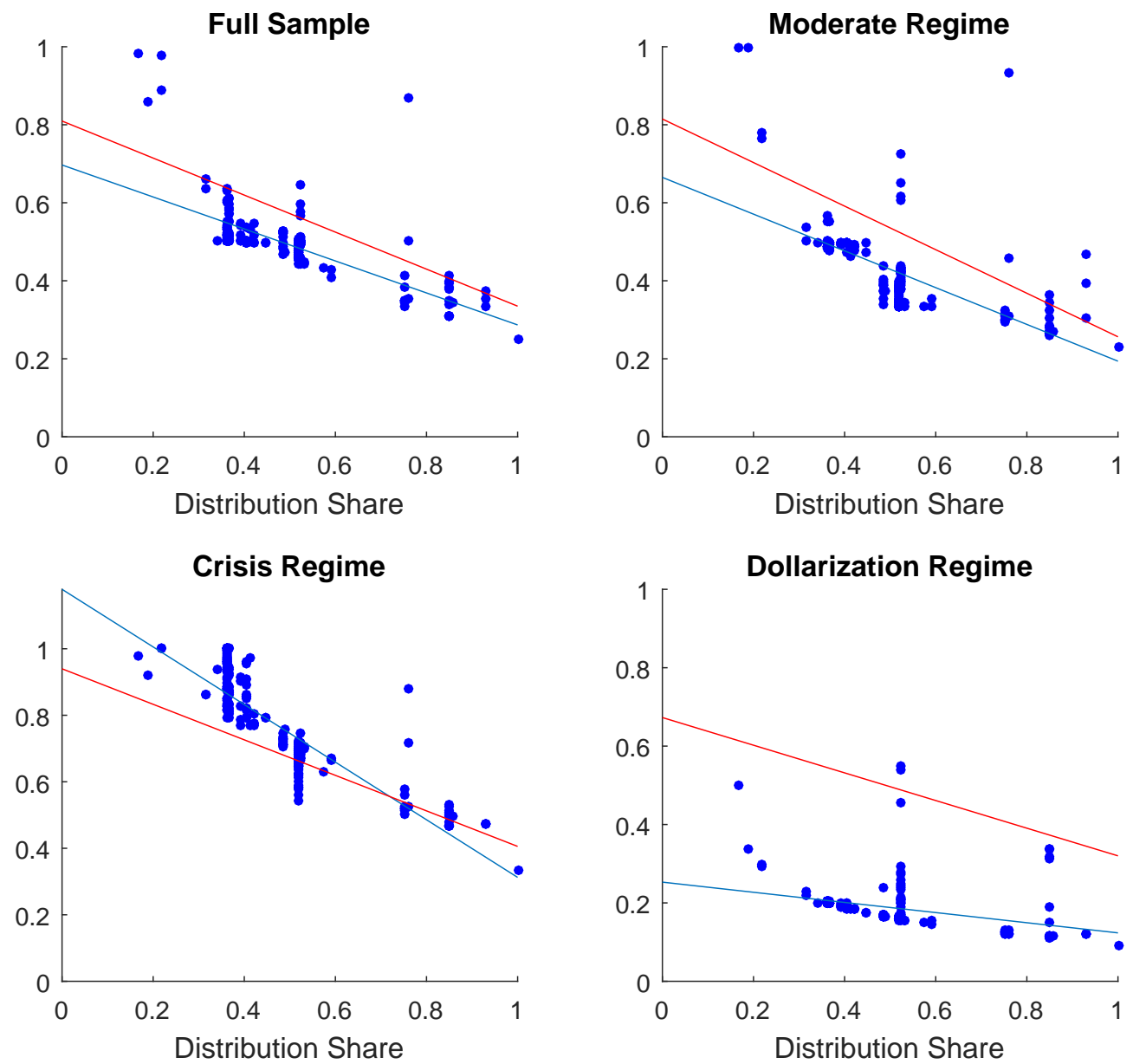

The frequency of price adjustment in each regime by distribution margin as predicted by our model. As was in the data, goods with a larger non-traded input share are less likely to reprice in each of the three regimes and the full sample. The red lines represent the trend lines in the data for reference. 